\title{
Fuzzy-based risk prioritization for a hydrogen refueling facility in Malaysia
}

\author{
Hue-yee $\mathrm{CHONG}^{\dagger}$, Mahidzal DAHARI, Hwa-jen YAP, Ying-tai LOONG \\ (Department of Mechanical Engineering, Faculty of Engineering, University Malaya, Kuala Lumpur 50603, Malaysia) \\ †E-mail: chonghy@um.edu.my \\ Received Apr. 8, 2013; Revision accepted July 9, 2013; Crosschecked July 10, 2013
}

\begin{abstract}
Hydrogen is starting to be mentioned as an alternative fuel to replace the fossil fuel in future transportation applications due to its characteristics of zero greenhouse gas emission and high energy efficiency. Before hydrogen fuel and its facilities can be introduced to the public, relevant safety issues and its hazards must be assessed in order to avoid any chance of injury or loss. While a traditional risk assessment has difficulty in prioritizing the risk of failure modes, this paper proposes a new fuzzy-based risk evaluation technique which uses fuzzy value to prioritize the risk of various scenarios. In this study, the final risk of each failure modes was prioritized by using the MATLAB fuzzy logic tool box with a combination of two assessments. The first assessment was concerned with the criteria which affected the actual probability of occurrence. This assessment considered the availability of the standard that was applied to prevent the likelihood of the scenario occurring. On the other hand, the second assessment was focused on evaluating the consequence of the failure by taking into account the availability of detection and the complexity of the failure rather than only the severity of the scenarios. A total of 87 failure scenarios were identified using failure modes and effect analysis (FMEA) procedures on hydrogen refueling station models. Fuzzy-based assessments were performed through risk prioritizing various failure scenarios with a fuzzy value ( 0 to 1$)$ and risk level (low, medium, and high) while a traditional risk assessment approach presented the risks only in forms of level (low, medium, and/or high). Availability of the fuzzy value enabled further prioritizing on the risk results that fell in the same level of risk. This study concluded that fuzzy-based risk evaluation is able to further prioritize the decisions when compared with a traditional risk assessment method.
\end{abstract}

Key words: Risk criteria, Risk prioritization, Hydrogen refueling facility, Fuzzy logic doi:10.1631/jzus.A1300114 Document code: A CLC number: TK91; TP391

\section{Introduction}

Fuel stations are considered as hazardous environments since they store and dispense flammable material such as petrol, compressed natural gas $(\mathrm{CNG})$, and hydrogen. Thus, it is important to have a safety and risk assessment model that can be applied to determine risks associated with fueling stations.

Since hydrogen is a highly explosive gas, being combustible over a wide range of concentrations, a number of risk assessments were carried out to verify the safety of hydrogen stations. For instance, a

\footnotetext{
* Project (No. D000023-16001) supported by the Malaysian Ministry of Higher Education (MOHE) High Impact Research Foundation (c) Zhejiang University and Springer-Verlag Berlin Heidelberg 2013
}

risk-informed approach has been used to show the utility of the station and also to identify the key variables that can influence the selection of safety distances (Lachance, 2009). Also, another study undertook a risk assessment to identify the safety issues of future hydrogen fueling stations for $70 \mathrm{MPa}$ fuel cell vehicles (Kikukawa et al., 2008). In addition, a risk assessment approach is used for liquid hydrogen fueling. A large number of failure mode and scenarios were identified using failure modes and effect analysis (FMEA) and a hazard and operability study (HAZOP) (Kikukawa et al., 2009). Risk assessment is a systematic process for assessing the impact and consequences of the occurrence for the human activities with hazardous characteristics. By considering the likelihood of the hazard and its severity, the risk of 
the particular hazard can be identified. Normally there will be three levels of risk: low, medium, and high risk In the current risk assessment carried out by other researchers, there is a difficulty in prioritizing the risk of the hazards which fall into the same categories. Besides, the lack of consideration of other risk criteria in contributing to the various risk magnitude was another problem that was identified.

In this study, the risk criteria that contribute to various risk evaluations were identified. Then, a risk prioritizing methodology for hydrogen refueling facilities was investigated. First, a small-scaled hydrogen refueling station model was assumed. Next, the failure modes or hazards of each of the sub-systems in the hydrogen refueling station was identified and analyzed. Then, their relative importance among the different risk criteria was identified. Lastly, a fuzzy logic technique was applied in evaluating the risk of each hazard due to an increasing number of risk criteria as well as prioritizing the risk of hazards. This paper describes the risk evaluation for a hydrogen refueling facility by using a systematic decisionmaking technique.

\section{Risk assessment of the hydrogen refueling station}

Risk analysis is simply a process that is used to assess the various types of risk associated with a given industrial activity when exposed to hazardous materials. It provides reasonable estimates of potential failure scenarios based on the frequency of occurrence and the magnitude of their impact (Casal, 2007). It is important to determine the failure modes or hazards that have greater risk for causing harm or injury. A high risk failure mode may require comprehensive control measures and precautions to prevent harm while a low risk hazard may reduce excessive control and save costs.

The methodology performed in the risk assessment is shown in Fig. 1. First, the type and scale of the hydrogen station model was defined. Then, the detailed failure modes of a hydrogen facility were identified and analyzed. Next, the relative importance among the risk criteria was identified. Lastly, a systematic decision-making tool, MATLAB fuzzy logic tool box, was applied in evaluating the risk for each failure mode and thus prioritizing them. As a result, the personnel are able to allocate the control and precautions accurately and efficiently based on the risk prioritization.

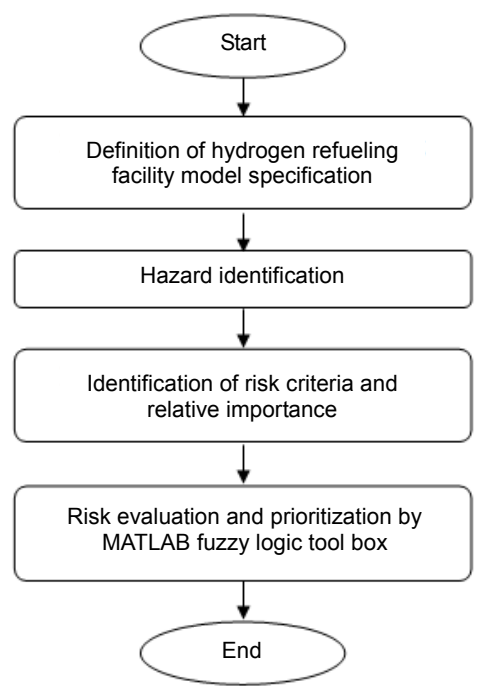

Fig. 1 Procedure of methodology in the risk evaluation

\subsection{Hydrogen refueling station}

There are three different system configurations available for a hydrogen refueling station based on the fueling capacity: small, medium, and large. Apart from this, a variety of hydrogen production options are available such as steam reforming, coal and biomass gasification as well as water electrolysis technology (Ni et al., 2006). Presently hydrogen can be stored as compressed gas, cryogenic liquid or as a solid combined with a metal hybrid (EERE Group, 2011).

Since Malaysia is in the initial development of this technology, we focused our research here on a small-scale hydrogen refueling system for vehicle transportation. As a result, a small-scale gaseous hydrogen refueling facility with on-site generation of hydrogen by electrolysis technology was investigated. Gaseous fuel stations typically consist of equipment for supply, compression, storage, and dispensing of fuel. Fig. 2 presents an overview of the schematic diagram of a refueling station considered in the later part of the hazard identification analysis.

\subsection{Identification of failure scenarios}

Different techniques have been introduced to identify failure scenarios and hazards including an HAZOP, fault tree analysis (FTA), as well as FMEA. 


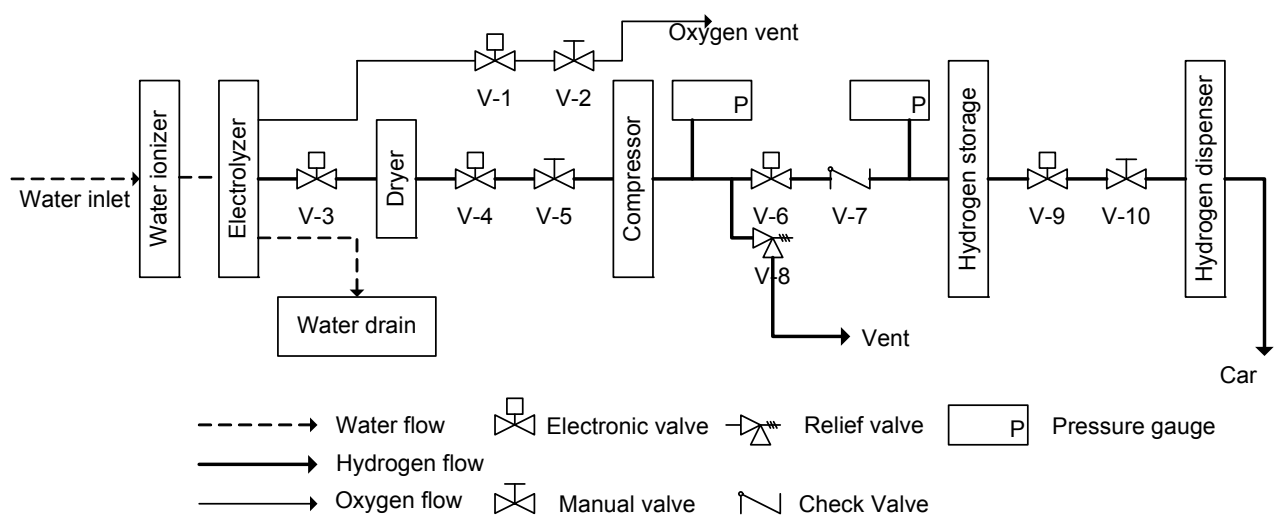

Fig. 2 Overview of the schematic diagram of the refueling stations

FMEA is a widely used technique to define and identify the possible ways of failure, along with problems and errors from the basic components and equipment of the system. This could result in either an equipment level or a functional level failure (Stamatis, 2003).

It is important to include more failure scenarios and examine them in detail in order to determine the critical failure scenarios accurately. After making an exhaustive list of failure scenarios and eliminating redundancy, 87 failure scenarios associated with hydrogen refueling facilities were identified. Among all, 21 failure modes were recognized as the common failure scenarios between sub-systems. For instance, internal leakage of a check valve is one of the common failure scenarios for hydrogen production, storage and dispensing sub-systems. The highest number of failure modes was identified in hydrogen production sub-systems which consist of 37 failure scenarios. Next, 36 failure scenarios were identified in the hydrogen storage sub-system and 32 failure scenarios were identified in the compression equipment. Lastly, only 21 failure scenarios were identified in the dispensing sub-systems. Fig. 3 shows the summary of hazards identified from FMEA.

\subsection{Risk criteria}

Risk criteria are used to indicate and evaluate the significance of risk on the events or scenarios considered (ISO, 2009). In risk assessment, occurrence and severity of the failure scenarios involved are usually the main risk criteria or factors that are used (OSHA Group, 2008). In this study, three new risk criteria were included: availability of detection, standards, and the complexity of scenarios.

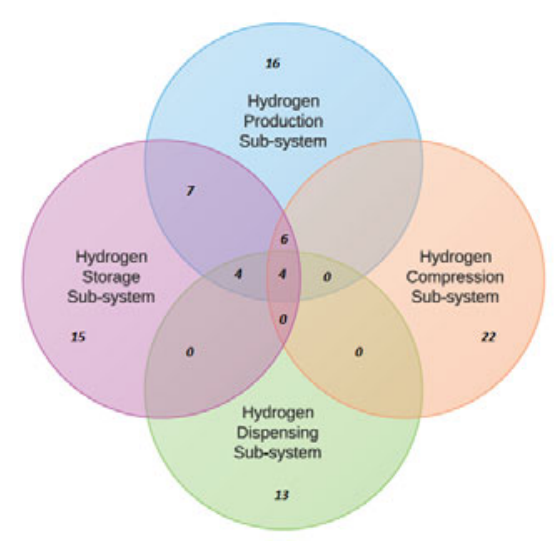

Fig. 3 Summary of hazard identified from FMEA

\subsubsection{Common risk criteria}

Likelihood is defined as the probability of an event occurring and is normally expressed in terms of frequency of occurrence or failure rate (per year or per $10^{6}$ hour) (OSHA Group, 2008). It is an estimate based on the historical data that was surveyed and collected over the years on various failure frequencies of the components. However, there is insufficient relevant statistics and data that can be applied for a hydrogen fuel component. Therefore, the general component reliability data such as OREDA offshore reliability data (SINTEF, 2009), Non-Electronic Parts Reliability Data (Denson et al., 1991), Component Reliability Data for Use in Probabilistic Safety Assessments (IAEA Group, 1988), and EGIG Gas Pipeline Incidents (EGPI Group, 2011) were used in this study. The likelihood levels used in this study are shown in Table 1.

Severity is defined as the extent of damage caused by an unwanted accident or event (OSHA 
Group, 2008). The damage can be in the form of material loss, human injury or environmental degradation. Presently, severity of failure mode is measured in a qualitative form instead of quantitative. Therefore, information from various sources was gathered and considered in this study. Hydrogen Incident Reporting Tool (HIRD Group, 2012) is one of the useful tools which consist of previous hydrogen system incidents and other relevant information gained from actual experiences. Besides, severity level and information from the California Energy Commission technical consultant report was included and considered as well (Shyam Venkatesh and Stefan Unnasch, 2004). Table 2 shows the severity levels used in the study.

\subsubsection{Detection, standard, and complexity}

Detection is defined as the probability of the failure being detected by safety mechanisms before the occurrence of the failure modes (Shyam Venkatesh and Stefan Unnasch, 2004). In FMEA, besides occurrence and severity of failure scenarios, detection levels are also incorporated to formulate the risk priority number (RPN), and thus determine the risk priorities of failure scenarios (Scipioni et al., 2002). When assessing operating reliability, detection becomes significant and should be included in risk evaluation. The proper inspection method or equipment is necessary in the hydrogen refueling station in order to prevent any unwanted incidents. Detection level indicates the ability of planned tests and inspections to remove defects or detect failure modes in sufficient time. Table 3 shows the detection levels used.

Standard is a sum of technical guidelines and rules that is established to ensure the quality of equipment or processes (ETSI Group, 2012). It protects the public and users by setting up the minimum acceptable level of safety for a new building, products, and processes. When hydrogen is being planned to be produced, stored, distributed and used on a large scale in the energy sector as an intermediate fuel, safety standards and codes are required. Through these codes of practice, users will be equipped with more knowledge and information on safety issues from its production, installation and until the maintenance of the hydrogen facility. Thus, the level of risk is affected by the availability of the related standards and codes. The standards reviewed include IGC Doc 15/06/E Gaseous Hydrogen Stations (EIGA Group, 2006), NFPA 52 Vehicular Gaseous Fuel

Table 2 Severity level (Norsk Hydro Asa and Det Norske Veritas (DNV), 2003)

\begin{tabular}{|c|c|c|}
\hline Level & Description & Definition \\
\hline A & Negligible & Minor material damage \\
\hline B & Minor & $\begin{array}{l}\text { Minor structural damage, minor pro- } \\
\text { duction influence }\end{array}$ \\
\hline $\mathrm{C}$ & Serious & $\begin{array}{l}\text { Considerable structural damage, pro- } \\
\text { duction interrupted for weeks }\end{array}$ \\
\hline $\mathrm{D}$ & Fatal & $\begin{array}{l}\text { Loss of main part of station, production } \\
\text { interrupted for months }\end{array}$ \\
\hline $\mathrm{E}$ & Catastrophic & $\begin{array}{l}\text { Total loss of station and major struc- } \\
\text { tural damages outside station area }\end{array}$ \\
\hline
\end{tabular}

Table 3 Detection levels used

\begin{tabular}{ccc}
\hline Level Description & \multicolumn{1}{c}{ Definition } \\
\hline A & Available & $\begin{array}{l}\text { Detection available for both occur- } \\
\text { rence and consequence of the failure } \\
\text { mode } \\
\text { Detection available for either occur- } \\
\text { rence or consequence of the failure } \\
\text { mode } \\
\text { Detection unavailable for both occur- } \\
\text { rence and consequence of the failure } \\
\text { mode }\end{array}$ \\
\hline
\end{tabular}

Table 1 Likelihood level (Norsk Hydro Asa and Det Norske Veritas (DNV), 2003)

\begin{tabular}{|c|c|c|c|c|}
\hline Level & Description & Definition & Frequency in years & $\begin{array}{l}\text { Frequency in hours } \\
\text { (per } 10^{6} \text { hour) }\end{array}$ \\
\hline A & Improbable & $\begin{array}{l}\text { Possible, but may not be heard of, or maybe } \\
\text { experienced world wide }\end{array}$ & 1 per 1000 year & $0-0.114$ \\
\hline B & Remote & $\begin{array}{l}\text { Unlikely to occur during lifetime/operation } \\
\text { of one filling station }\end{array}$ & 1 per 100 year & $0.115-1.142$ \\
\hline $\mathrm{C}$ & Occasional & $\begin{array}{l}\text { Likely to occur during lifetime/operation of } \\
\text { one filling station }\end{array}$ & 1 per 10 year & $1.143-11.415$ \\
\hline $\mathrm{D}$ & Probably & May occur several times at the filling station & 1 per 1 year & $11.416-114.156$ \\
\hline $\mathrm{E}$ & Frequently & Will occur frequently at the filling station & 10 per year & $114.157-1141.553$ \\
\hline
\end{tabular}


Systems Code (NFPA Group, 2010), ASME Boiler and Pressure Vessel Code (ASME Group, 2010) and others. The standard levels are shown in Table 4.

Complexity is difficult to define since there is no standardized definition of complexity in the sciences of complexity (Gell-Mann, 1995). From the dictionary, complexity is defined as the state or quality of being complex. It is important to view or consider the complexity of failure in a system (Dekker et al., 2011). Thus, in the current study, complexity of the failure scenarios is considered as one of the criteria which affect the risk value. The level of the complexity in this study was then measured by the number of personnel needed to perform the maintenance steps as well as the number of steps required for the maintenance to take place. Table 5 shows this complexity level.

Table 4 Standard level

\begin{tabular}{ccc}
\hline Level & Description & \multicolumn{2}{c}{ Definition } \\
\hline A & Available & $\begin{array}{c}\text { Standard available for both equip- } \\
\text { ment and failure mode of the } \\
\text { equipment } \\
\text { Standard available for either equip- } \\
\text { ment or failure mode of the equip- } \\
\text { ment }\end{array}$ \\
C & Medium & $\begin{array}{c}\text { Standard unavailable for both equip- } \\
\text { ment and failure mode of the } \\
\text { equipment }\end{array}$ \\
\hline
\end{tabular}

Table 5 Complexity level

\begin{tabular}{|c|c|c|}
\hline Level & Description & Definition \\
\hline A & Simple & $\begin{array}{l}\text { Usually requires single personnel to } \\
\text { perform one-step maintenance to a } \\
\text { single piece, part, component, sub- } \\
\text { assembly, and assembly }\end{array}$ \\
\hline B & Medium & $\begin{array}{l}\text { Usually requires single personnel to } \\
\text { perform multiple step maintenance } \\
\text { to a multiple pieces, parts, compo- } \\
\text { nents, subassemblies, and assem- } \\
\text { blies }\end{array}$ \\
\hline $\mathrm{C}$ & Complex & $\begin{array}{l}\text { Usually requires a team of personnel } \\
\text { to perform multiple step mainte- } \\
\text { nance to a multiple piece, parts, } \\
\text { components, subassemblies, and } \\
\text { assemblies }\end{array}$ \\
\hline
\end{tabular}

\subsection{Risk evaluation}

Each failure mode is evaluated according to the definition stated in Tables 1 to 5 with appropriate levels of likelihood, severity, detection, standard, and complexity. The risk evaluation, through using a MATLAB fuzzy logic tool box with a relative input weightage, is summarized in Fig. 4. The first assessment is more concerned with the criteria which affect the actual probability of occurrence by considering the availability of the standard that is applied to prevent the various scenarios, besides likelihood (failure rate). Then, the second assessment is focused on evaluating the consequences of the failure by taking into account the availability of detection and the complexity of the failure rather than only the severity of the scenarios. Thus, the combination of both assessments will generate the final risk value ( 0 to 1) and the risk rating (low, medium and high). The relative risk rating can be used to prioritize necessary actions to effectively manage work place hazards. A rating of HIGH risk requires immediate action to control the hazard as detailed in the hierarchy of control. For instance, these hazards should be eliminated or substituted with a safer alternative. Next, a MEDIUM risk requires a planned approach to controlling the hazard and applying a temporary measure if required. For example, equipment should be tested or inspected on a regular basis for any required maintenance. Lastly, a risk identified as LOW may be considered as acceptable and further reduction may not be necessary.

\section{Fuzzy multiple-criteria decision-making}

Fuzzy logic variables can have intermediate numeric values between conventional evaluations like true or false, yes or no, high or low, etc. The difference between a traditional set and a fuzzy set is the degree of membership. For a traditional set, an element has either a full membership or no membership at all, while fuzzy sets allow for partial membership. Fuzzy logic has been extensively used in risk assessment especially when there is a lack of reliable data. A case study was done to compare the traditional results obtained by explosion layer of protection analysis (ExLOPA) and by fuzzy ExLOPA methods in explosion assessment. The case study proves that fuzzy-based assessments provide better decisions and better insights for each explosion risk scenario if multiple risk factors are included (Markowski et al., 2011). A pure fuzzy logic system is used as an 
alternative approach to compare with the traditional analysis parameter, risk priority number (RPN) in the risk assessment on nuclear engineering systems. The study showed that the fuzzy approach is able to provide a more accurate ranking and identified the priorities for the containment cooling system (Guimarães and Lapa, 2007). Again, fuzzy methods enable a better assessment of the accident scenarios, proper calculation of the risk index and more appropriate selection of safety measures required to meet risk acceptance criteria (Markowski et al., 2009). Besides, fuzzy technology can be applied in assessment of noise exposure risks in an industrial workplace (Golmohammadi et al., 2011), determine risks of urban natural hazards (Huang, 1996), and assess risks of pollution derived from the presence of ecotoxic substances in hazardous plants (Darbra et al., 2008) as well as risk assessments of river-type hydro power plants (Bonvicini et al., 1998).

\subsection{Fuzzy membership function}

In this study, a MATLAB fuzzy logic toolbox simulator was used to perform the risk evaluation. As shown in Fig. 4, the risk assessment consists of three multi-input and single-output scenarios. First, a multiinput vector, $\boldsymbol{x}$ and a single output vector, $\boldsymbol{y}$ are defined as

$$
\begin{aligned}
& \boldsymbol{x}=\left[x_{1}, x_{2}, \ldots, x_{n}\right]^{\mathrm{T}}, \\
& \boldsymbol{y}=\boldsymbol{y}_{1}{ }^{\mathrm{T}} .
\end{aligned}
$$

The linguistic variable $x_{i}$ in the universe of discourse $U$ is characterized by

$$
\begin{aligned}
& T(\boldsymbol{x})=\left\{T_{x}^{1}, T_{x}^{2}, \ldots, T_{x}^{k}\right\}, \\
& \mu(\boldsymbol{x})=\left\{\mu_{x}^{1}, \mu_{x}^{2}, \ldots, \mu_{x}^{k}\right\},
\end{aligned}
$$

where $T(\boldsymbol{x})$ is a term set of $\boldsymbol{x}$; that is, it is the set of names of linguistic values of $\boldsymbol{x}$ with each $T_{x}^{i}$ being a fuzzy member and the membership function $\mu_{x}^{i}$ defined on $U$.

A membership function is essentially a curve that defines how each point in the input space is mapped to a membership value (or degree of membership) between 0 and 1 . The triangular membership function was used in the study.

Let the inputs $x_{1}$ represent the likelihood of failure modes in $10^{6} \mathrm{~h}, T\left(x_{1}\right)$ represent its term set \{improbable, remote, occasional, probably, frequent\}, and the universe of discourse be 0 to 1 . Fuzzy membership functions representing likelihood are shown in Fig. 5.

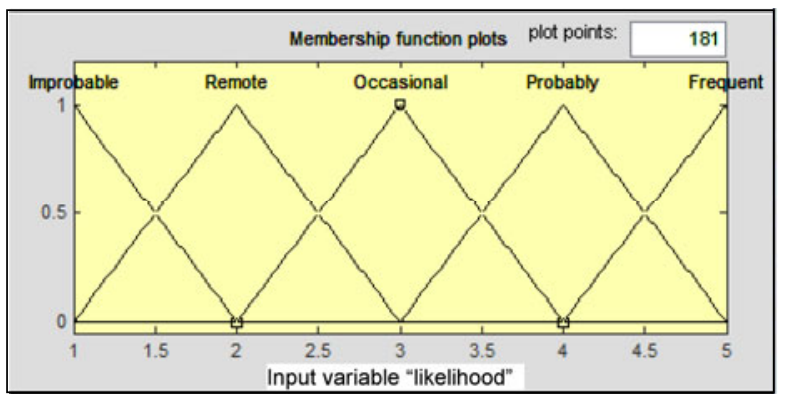

Fig. 5 Fuzzy membership functions of likelihood

First assessment

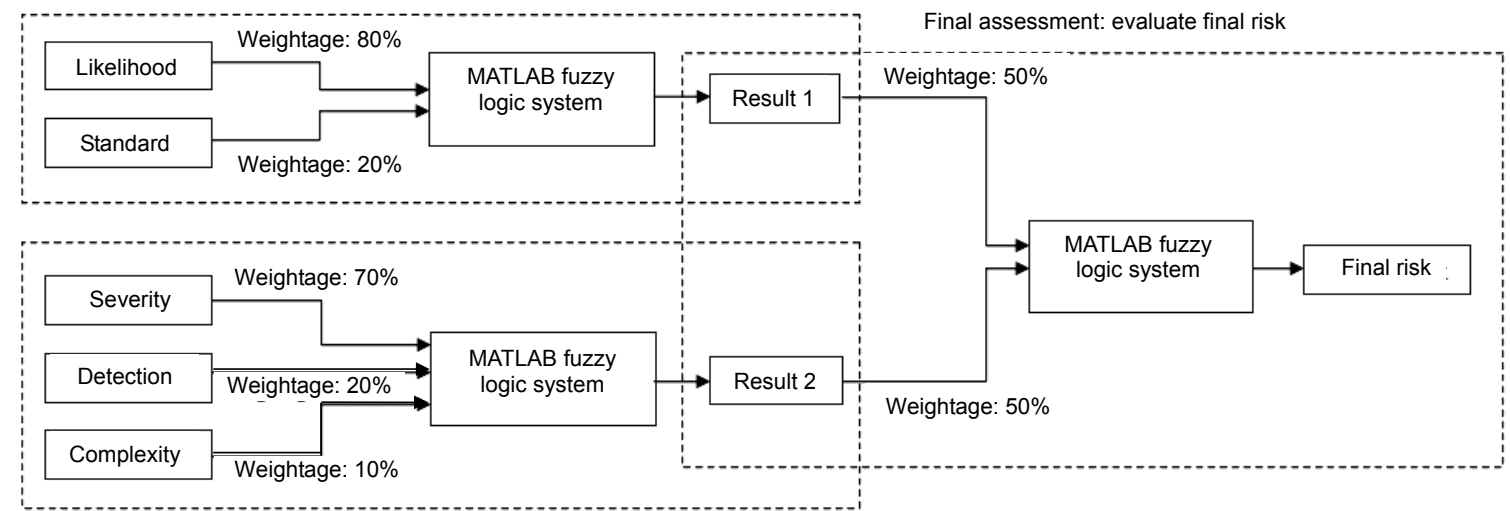

Second assessment

Fig. 4 Risk evaluation with weighted risk factor 


\subsection{If-then rules}

The set of linguistic rules in the form of "if-then" rules which represent the relationships between the input and output variables were formed. The formation of the if-then rules is based on the expert knowledge and the database of the input-output history. The numbers of rules obtained for the first and second assessments are 15 rules and 45 rules, respectively. By using the same method, 25 rules were defined for the final risk assessment.

\subsection{Fuzzy inference system (FIS)}

Fuzzy-based risk assessment techniques map human knowledge in linguistic terms into quantitative and realistic values by the application of a fuzzy logic system (FLS). The inference process can be described completely in five steps. Firstly, the degree to which the input belongs to each was determined for each of the appropriate fuzzy sets by a membership function (fuzzification). Secondly, fuzzy logical operators are applied to evaluate the composite firing strength of the rule. As a result, each fuzzy rule yields a single number that represents the firing strength of that rule. Thirdly, the shaping of the output fuzzy set of each of the rules is defined (implication). Next, the outputs of each rule are unified (aggregation). Lastly, a centroid defuzzification process takes place. This is the most extensively used technique and it provides an accurate value (Yen and Langari, 1999). Fuzzy numbers need to be defuzzified into an exact numerical value for risk evaluation categories and for ranking purposes.

The fuzzy inference process defines the mapping surface. As an illustration, the mapping surface of the first assessment is shown in Fig. 6.

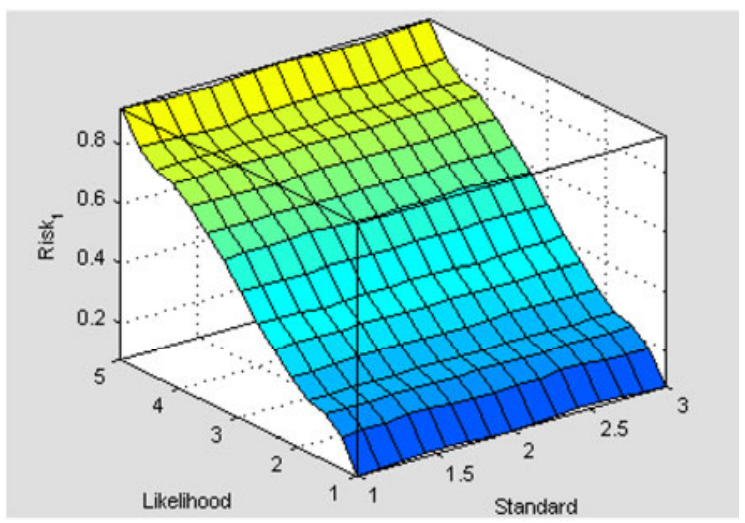

Fig. 6 Mapping surface of first assessment

\section{Result and discussion of risk assessment}

A fuzzy-based risk evaluation, by using two traditional variables (likelihood and severity) and three new added variables (standard, detection, and complexity) was assessed. Fig. 7 shows the distribution of the result of 87 failure modes. From this figure, $60 \%$ of the failure modes or 52 failure scenarios are identified with the rating of HIGH risk, and immediate action is needed to control the hazard.

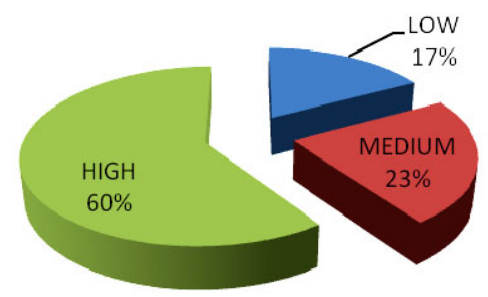

Fig. 7 Risk level of failure modes identified

\subsection{Comparison of proposed fuzzy-based risk evaluation and rapid risk ranking}

This study further prioritizes 52 failure scenarios by using the fuzzy value. The fuzzy-based risk evaluation method shows the output in the form of the fuzzy value and the risk level. On the other hand, a traditional rapid risk ranking performed the assessment qualitatively. Although all failure scenarios in the table are in HIGH risk, the fuzzy method shows the advantages over the traditional risk results by providing a fuzzy number. Availability of the fuzzy number enables further prioritizing of the risk result that falls in the same level of risk. For example, fuzzy-based risk evaluation results show that a seal leakage of the compressor has greater risk than the membrane thinning of a polymer electrolyte membrane (PEM) cell stack, although both of the scenarios are in HIGH risk. Fuzzy-based risk evaluation techniques help in defining the risk of the failure modes in more realistic ways by using a fuzzy value. The top ten failure modes and the comparison with traditional rapid risk ranking are shown in Table 6.

\subsection{Comparison of two risk criteria and a proposed five risk criteria fuzzy-based risk assessment}

Furthermore, a fuzzy-based risk assessment is used to compare the risk result of a traditional risk 
assessment by considering two risk criteria (severity and likelihood) and five risk criteria (likelihood, standard, severity, detection, and complexity). Examples of the risk results are shown in Table 7 . The first failure scenario in Table 7 shows a fuzzy value decrease from 0.7859 to 0.7500 when new risk criteria are considered in the assessment. This is mainly due to the availability of the detection mechanism and standard to protect the component. On the other hand, the risk value of the compressor internal corrosion increases from 0.7516 to 0.7529 due to the high complexity of the failure, the unavailability of the detection mechanism as well as the lack of standard and regulation to protect the component. The newly identified risk criteria examine the failure by considering more relevant criteria.

\subsection{Significance of the newly added risk criteria}

By comparing the fuzzy-based risk evaluation (five criteria) and the traditional rapid risk ranking, twenty scenarios identified show a different level of risk assigned (Table 8). Failure scenarios with higher risk levels in a fuzzy-based risk assessment are mainly due to the unavailability of the detection mechanism and high complexity of failure. Lack of standard and regulation to protect the component also contribute to the variation. On the other hand, the failure scenarios receiving a lower risk level in the fuzzy-based risk assessment is due to the availability of the guidelines that ensure the quality of equipment and safety mechanisms to detect the failure scenarios before its occurrence. The three newly identified risk criteria play an important role to provide more information for the current risk evaluation.

\section{Conclusions}

The traditional risk assessment has difficulty in prioritizing the risk of the failure modes. This paper proposed a new fuzzy-based risk evaluation technique which uses the fuzzy value to prioritize the risk of the scenarios. A total of 87 failure scenarios were identified using FMEA procedures on hydrogen refueling station models. Besides severity and likelihood levels, availability of standard and detection as well as the complexity of the failure scenarios were also considered in the study. Results show that $60 \%$ of the failure modes with the designation of HIGH risk after all

Table 7 Comparison of fuzzy-based risk evaluation results by using two risk criteria and five risk criteria

\begin{tabular}{lccl}
\hline Failure scenario & $\begin{array}{c}\text { Fuzzy-based } \\
\text { with two risk } \\
\text { criteria }\end{array}$ & $\begin{array}{c}\text { Fuzzy-based } \\
\text { with five } \\
\text { risk criteria }\end{array}$ & Remark \\
\hline $\begin{array}{l}\text { Over pressuriza- } \\
\text { tion of elbow/joint }\end{array}$ & 0.7859 & 0.7500 & $\begin{array}{l}\text { Risk value } \\
\text { decrease }\end{array}$ \\
$\begin{array}{c}\text { Compressor in- } \\
\text { ternal corrosion }\end{array}$ & 0.7516 & 0.7529 & $\begin{array}{l}\text { Risk value } \\
\text { increase }\end{array}$ \\
$\begin{array}{c}\text { Pinhole formation } \\
\text { of PEM cell stack }\end{array}$ & 0.7500 & 0.7500 & $\begin{array}{l}\text { Risk value } \\
\text { unchanged }\end{array}$ \\
\hline
\end{tabular}

Table 8 Distribution of failure scenarios with different level of risk assigned

\begin{tabular}{lccc}
\hline $\begin{array}{c}\text { Risk } \\
\text { rating }\end{array}$ & $\begin{array}{c}\text { No. of failure } \\
\text { scenarios by } \\
\text { traditional rapid } \\
\text { risk ranking }\end{array}$ & $\begin{array}{c}\text { No. of } \\
\text { variation }\end{array}$ & $\begin{array}{c}\text { No. of failure } \\
\text { scenarios by } \\
\text { fuzzy-based } \\
\text { assessment }\end{array}$ \\
\hline Low & 15 & $\uparrow 3$ & 15 \\
Medium & 8 & $\downarrow 3 \uparrow 1$ & 20 \\
High & 64 & $\downarrow 13$ & 52 \\
\hline Total variation & $\uparrow 4 \downarrow 16$ & \\
\hline
\end{tabular}

Table 6 Comparison of fuzzy-based risk evaluation result and rapid risk ranking result

\begin{tabular}{llccccc}
\hline \multirow{2}{*}{ Sub-system } & \multicolumn{2}{c}{ Failure scenario } & \multicolumn{2}{c}{ Rapid risk ranking } & & \multicolumn{2}{c}{ Proposed fuzzy-based } \\
\cline { 3 - 4 } \cline { 5 - 6 } & & Risk level & Risk value & & Risk level & Final risk \\
\hline Compressor & Seal leakage & High & - & High & 0.7887 \\
Compressor & Leak/Rupture & High & - & High & 0.7887 \\
Dispenser & Dispenser cascade control failure & High & - & High & 0.7887 \\
Storage vessel & External corrosion & High & - & High & 0.7874 \\
Compressor & Internal corrosion & High & - & High & 0.7529 \\
Compressor & Sealing material deterioration & High & - & High & 0.7529 \\
$\mathrm{H}_{2}$ gas piping & Hydrogen embrittlement of piping material & High & - & High & 0.7510 \\
Elbow/joint & Over pressurization & High & - & High & 0.7500 \\
PEM cell stack & Membrane thinning & High & - & & High & 0.7500 \\
PEM cell stack & Pinhole formation & High & - & & High & 0.7500 \\
\hline
\end{tabular}


five risk factors have been considered. Fuzzy-based risk evaluations further prioritize the $52(60 \%)$ failure scenarios by using the fuzzy value. Fuzzy-based risk evaluation techniques help in defining the risk of failure modes in more realistic ways and improve the current risk evaluation results.

\section{References}

ASME Group, 2010. ASME Boiler and Pressure Vessel Code. American Society of Mechanical Engineers (ASME).

Bonvicini, S., Leonelli, P., Spadoni, G., 1998. Risk analysis of hazardous materials transportation. Journal of Hazardous Materials, 62:59-74.

Casal, J., 2007. Evaluation of the Effects and Consequences of Major Accidents in Industrial Plants. Elsevier Science.

Darbra, R.M., Demichela, M., Murè, S., 2008. Preliminary risk assessment of ecotoxic substances accidental releases in major risk installations through fuzzy logic. Process Safety and Environmental Protection, 86(2):103-111. [doi:10.1016/j.psep.2007.10.015]

Denson, W., Chandler, G., Crowell, W., Wanner, R., 1991. Non-electronic Parts Reliability Data. Available from http://www.dtic.mil/dtic/tr/fulltext/u2/a242083.pdf [Accessed on Aug. 15, 2012].

Dekker, S., Cilliers, P., Hofmeyr, J.H., 2011. The complexity of failure: Implications of complexity theory for safety investigations. Safety Science, 49(6):939-945. [doi:10. 1016/j.ssci.2011.01.008]

EERE Group, 2011. Current Technology of Hydrogen Storage. Available from http://www1.eere.energy.gov/hydrogen andfuelcells/storage/current_technology.html [Accessed on June 10, 2012].

EIGA Group, 2006. IGC Doc 15/06/e Gaseous Hydrogen Stations. European Industrial Gases Association (EIGA).

ETSI Group, 2012. What Are Standards? Available from http://www.etsi.org/standards/what-are-standards [Accessed on June 21, 2012].

Gell-Mann, M., 1995. What is complexity. Complexity, 1(1): 16-19.

Golmohammadi, R., Eshaghi, M., Khoram, M.R., 2011. Fuzzy logic method for assessment of noise. International Journal of Occupational Hygiene, 3(2):49-55.

Guimarães, A.C.F., Lapa, C.M.F., 2007. Fuzzy inference to risk assessment on nuclear engineering systems. Applied Soft Computing, 7(1):17-28. [doi:10.1016/j.asoc.2005. 06.002]

HIRD Group, 2012. $\mathrm{H}_{2}$ Incident Reporting and Lessons Learned. Available from http://www.h2incidents.org/ [Accessed on Aug. 5, 2012].

Huang, C., 1996. Fuzzy risk assessment of urban natural hazards. Fuzzy Sets and Systems, 83(2):271-282.
ISO, 2009. ISO 31000 Translated into Plain English. International Organization for Standardization (ISO).

Kikukawa, S., Yamaga, F., Mitsuhashi, H., 2008. Risk assessment of hydrogen fueling stations for $70 \mathrm{MPa}$ FCVs. International Journal of Hydrogen Energy, 33(23):71297136. [doi:10.1016/j.jhydene.2008.08.063]

Kikukawa, S., Mitsuhashi, H., Miyake, A., 2009. Risk assessment for liquid hydrogen fueling stations. International Journal of Hydrogen Energy, 34(2):1135-1141. [doi:10.1016/j.ijhydene.2008.10.093]

Lachance, J., 2009. Risk-informed separation distances for hydrogen refueling stations. International Journal of Hydrogen Energy, 34(14):5838-5845. [doi:10.1016/j. ijhydene.2009.02.070]

Markowski, A.S., Mannan, M.S., Bigoszewska, A., 2009. Fuzzy logic for process safety analysis. Journal of Loss Prevention in the Process Industries, 22(6):695-702. [doi:10.1016/j.jp.2008.11.011]

Markowski, A.S., Mannan, M.S., Kotynia, A., Pawlak, H., 2011. Application of fuzzy logic to explosion risk assessment. Journal of Loss Prevention in the Process Industries, 24(6):780-790. [doi:10.1016/j.jlp.2011.06.002]

NFPA Group, 2010. NFPA 52 Vehicular Gaseous Fuel Systems Code. National Fire Protection Association (NFPA).

Ni, M., Leung, M.K.H., Sumathy, K., Leung, D.Y.C., 2006. Potential of renewable hydrogen production for energy supply in Hong Kong. International Journal of Hydrogen Energy, 31(10):1401-1412. [doi:10.1016/j.ijhydene.2005. 11.005]

Norsk Hydro ASA, Det Norske Veritas (DNV), 2003. Risk Acceptance Criteria for Hydrogen Refuelling Stations. Available from http://www.eihp.org/public/documents/ acceptance_criteria_for_H2-refuelling_stations_FEB200 3.pdf [Accessed on May 17, 2012].

OSHA Group, 2008. Guidelines for Hazard Identification, Risk Assessment and Risk Control (HIRARC). Technical Report Department of Occupational Safety and Health (OSHA), Ministry of Human Resources, Malaysia.

Scipioni, A., Saccarola, G., Centazzo, A., Arena, F., 2002. FMEA methodology design, implementation and integration with HACCP system in a food company. Food Control, 13:495-501.

SINTEF, 2009. Offshore Reliability Data (OREDA), Volume 1-Topside Equipment. OREDA Participant. Available from http://www.sintef.no/oredahandbook.

Stamatis, D.H., 2003. Failure Mode and Effects Analysis: FMEA from Theory to Execution. ASQ Quality Press, USA.

Yen, J., Langari, R., 1999. Fuzzy Logic: Intelligence, Control, and Information. Pearson Education, USA. 